\title{
Communication
}

\section{A Note on the Baseline in Considering the Ice Age}

\section{Syun-Ichi Akasofu}

International Arctic Research Center, University of Alaska Fairbanks, 505 S Chandlar Dr, Fairbanks, AK 99775, USA; E-Mail: sakasofu@iarc.uaf.edu; Tel.: +1-907-474-6012; Fax: +1-907-474-5662

Received: 13 May 2014; in revised form: 17 June 2014 / Accepted: 17 June 2014 /

Published: 25 June 2014

\begin{abstract}
Shifting the presently used baselines of temperature changes during the last 440,000 years to about the lowest recorded temperature $\left(+5^{\circ} \mathrm{C}\right)$ as the baseline, a somewhat different view of climate change during the four Ice Ages emerges. Unlike the presently used baselines, the lowest temperature baseline is sort of the "absolute" one, in the sense that it does not depend on any chosen period during the last 440,000 years. Taking such a temperature as the baseline, the general trend of changes represents approximately the heat input function. Thus, in this view, the warming pulses with a sharp onset are the main feature, rather than a sequence of slow cooling and the subsequent sudden warming, although the basic physics involved in the feedback process may be the same. The interglacial periods are the peaks of the impulsive warming, rather than "returning to the normal condition" or "recovery from the Ice Ages". In fact, the commonly used baselines represent simply the present conditions, rather than the baseline in climatology.
\end{abstract}

Keywords: Ice Ages; interglacial period; baseline

\section{Introduction}

In meteorology and climatology, there is no absolute baseline from which anomalous deviations can be determined. It depends at least on a chosen period. In discussing the Ice Ages, it is generally believed that Ice Ages begin rather gradually from the commonly used baseline temperature, and reach their minimum temperature in about 75,000 years and that the recovery is rather abrupt, taking 10,000 years or less, and that the period between two Ice Ages, the interglacial period, lasts about 15,000 years.

The upper part of Figure 1 shows this standard view by modifying a black and white version of the figure in [1], by painting the period below the baseline blue and the period above the baseline red. In the figure (p.1 in [1]), the 1950 mean value is taken as the baseline value $\left(+15^{\circ}\right)$. The underlying 
consideration in this view is that the present condition is "normal", the baseline temperature being $+15{ }^{\circ} \mathrm{C}$, which is shown as the baseline (the $0{ }^{\circ} \mathrm{C}$ line) in Figure 1 . In fact, all the radiative balance considerations are discussed on such a basis [2-5]. However, the baseline value of the figure (p. 1 in [1]) is modified from $15{ }^{\circ} \mathrm{C}$ to $13{ }^{\circ} \mathrm{C}$ for the reason mentioned below.

In discussing climate change during the Ice Ages, there are two issues to be considered: the baseline temperature and the range of temperature changes. The global average temperature increased from $+13.7{ }^{\circ} \mathrm{C}$ to $+14.4{ }^{\circ} \mathrm{C}$ between 1850 and 2000 (Figure 1 in [6]). The most reasonable temperature may be the one based on the above fact and the net radiative balance (Chapter 6.8.2 in [7]) which is about $+13{ }^{\circ} \mathrm{C}$. The second issue is the range of temperature changes during the Ice Ages. Figure 1 is based on the records at Vostok, but the Greenland records show a larger range of temperature changes [8]; both were compared and discussed [9,10]. For these reasons, in Figure 1, we consider the zero-line temperature to be $13{ }^{\circ} \mathrm{C}$ and the range of temperature to be $8{ }^{\circ} \mathrm{C}$. In spite of such uncertainties, the basic argument in this paper is not affected. That is, it may be worthwhile to consider the lowest temperature during the last 440,000 years as the baseline.

Figure 1. In the upper part, based on the standard view, there were four successive Ice Ages (painted blue) during the last 440,000 years and the intervening interglacial periods (painted red). The original figure has a black and white format (Figure 1.5 in [1]). In the lower part, the base line is chosen to be $+5{ }^{\circ} \mathrm{C}$, and the whole range of changes is painted in red.

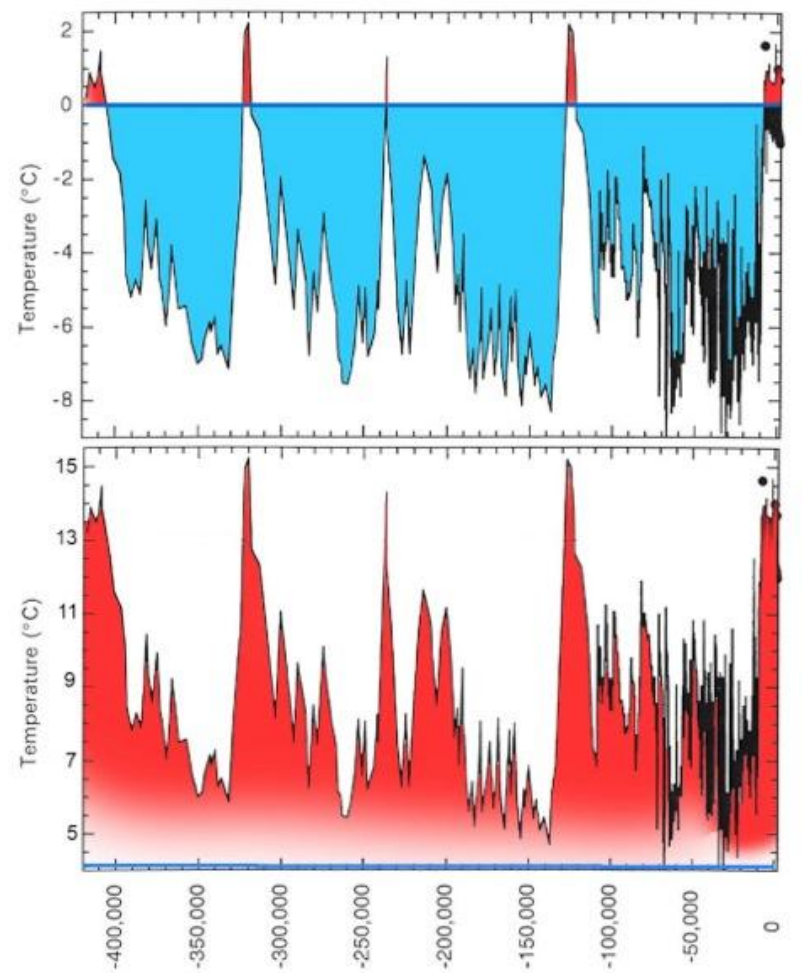

\section{New Baseline}

However, glancing at temperature changes during the last four Ice Ages, one realizes that other interpretations of the temperature changes may be possible, depending on the chosen baseline. First of 
all, Figure 1 shows that the lowest temperature level during the last 440,000 years is about $8{ }^{\circ} \mathrm{C}$ lower than $13{ }^{\circ} \mathrm{C}$. If we take this minimum temperature as the baseline temperature, it might be considered as sort of the "absolute" one, since it does not depend on any chosen period during the last 440,000 years. The lower part of Figure 1 is constructed by taking $+5{ }^{\circ} \mathrm{C}\left(=13{ }^{\circ} \mathrm{C}-8{ }^{\circ} \mathrm{C}\right)$ as the baseline.

In this view, the temperature changes during the last 440,000 years consisted of a sequence of four impulsive warming periods and the subsequent slow cooling (combining the first and the last ones). Thus, the combined change may represent approximately the heat input function to the earth system. Further, the interglacial period is the peak of the warming, rather than returning to the "normal" condition.

\section{Summary}

If we adopt the proposed baseline $\left(+5^{\circ} \mathrm{C}\right)$, it is close to the absolute baseline condition for at least 440,000 years; it does not depend on any chosen period. Although the basic physics involved in the feedback process may be the same for both views of the baseline, the new baseline view suggests that the trend of the temperature changes represents the heat input function. In this regard, it may be noted that there has been considerable progress on the astronomical effects on the earth's climate $[11,12]$. In particular, the time rate of changes of global ice volume agrees very well with summer time insolation in the northern latitudes, so that the direct solar input is now determined.

\section{Conflicts of Interest}

The author declares no conflict of interest.

\section{References}

1. Muller, R.A.; MacDonald, G.J. Ice Ages and Astronomical Causes: Data, Spectral Analysis and Mechanisms; Springer: New York, NY, USA, 2002; p. 318.

2. Graedel, T.E.; Crutzen P.J. Atmosphere, Climate, and Change; Scientific American Library: New York, NY, USA, 1995; p. 196.

3. Ruddiman, W.F. Earth's Climate: Past and Future; W.H. Freemen and Company: New York, NY, USA, 2001; p. 465.

4. Burroughs, W.J. Climate Change: A Multidisciplinary Approach; Cambridge University Press: Cambridge, UK, 1995; p. 298.

5. Tsuchida, A. Netsugaku Gairon; Asakura: Tokyo, Japan, 2008; p. 1-197. (In Japanese)

6. Mauritsen, T.; Stevens, B.; Roeckner, E.; Crueger, T.; Esch, M.; Giorgetta, M.; Haak, H.; Jungclaus, J.; Klocke, D.; Matei, D.; et al. Tuning the climate of a global model. J. Adv. Model. Earth Syst. 2012, doi:10.1029/2012MS000154.

7. Peixoto, J.P.; Oort, A.H. Physics of Climate; American Institute of Physics: New York, NY, USA, 1992; p. 520. 
8. Mayewski, P.A.; Meeker, L.D.; Whitlow, S.; Twickler, M.S.; Morrison, M.C.; Alley, R.B.; Bloomfield, P.; Taylor, K. The atmosphere during the Younger Dryas. Science 1993, 261, 195-197.

9. Jouzel, J.; Vaikmae, R.; Petit, J.R.; Martin, M.; Duclos, Y.; Stievenard, M.; Lorius, C.; Toots, M.; Mélières, M.A.; Burckle, L.H.; et al. The two-step shape and timing of the last deglaciation in Antarctica. Clim. Dyn. 1995, 11, 151-161.

10. Intergovernmental Panel on Climate Change (IPCC). Climate change 1995: The science of climate change. Weather 1996, 51, doi:10.1002/j.1477-8696.1996.tb06169.x.

11. Edvardsson, S.; Karlsson, K.G.; Engholm, M. Accurate spin axes and solar system dynamics: Climate variations for the earth and Mars. Astrom. Astrophys. 2002, 384, 689-701.

12. Roe, G. In defense of Milankovitch. Gophys. Res. Lett. 2006, doi:10.1029/2006GL027817.

(C) 2014 by the authors; licensee MDPI, Basel, Switzerland. This article is an open access article distributed under the terms and conditions of the Creative Commons Attribution license (http://creativecommons.org/licenses/by/3.0/). 